\title{
Projeto de rede de distribuição de energia elétrica, mapeamento e estudo de impacto de demanda do Campus de Cachoeira do Sul da Universidade Federal de Santa Maria
}

\author{
Project of Distribution Network of Electrical Energy, Mapping and Study of Demand Impact \\ of the Federal University of Santa Maria, Campus of Cachoeira do Sul
}

Stephanie Pastorelli Biasotto ${ }^{1}$, Fernando Guilherme Kaehler Guarda² e Criciéle Castro Martins ${ }^{3}$

${ }^{1}$ Universidade Federal de Santa Maria, Cachoeira do Sul, Brasil

Stephanie.p.biasotto@gmail.com

${ }^{2}$ Universidade Federal de Santa Maria, Cachoeira do Sul, Brasil

fernadkg@gmail.com

${ }^{3}$ Universidade Federal de Santa Maria, Santa Maria, Brasil

cricielecastro@gmail.com

\section{Resumo}

Há cerca de quatro anos, o Campus da Universidade Federal de Santa Maria, localizado na cidade de Cachoeira do sul, está ativo e suas atividades são feitas de modo provisório em imóveis na região central e próxima ao centro. O Campus está atualmente em andamento com sua construção que receberá docentes, discentes e servidores técnico-administrativos e iniciará com cinco cursos de graduação, sendo que os mesmos já estão em atividade nos móveis provisórios. Um projeto de rede de distribuição de energia elétrica consiste em melhorar o funcionamento do Campus, levando em conta que como ainda está em construção, o Campus possui energia elétrica fornecida de modo provisório. A proposta do projeto suprirá a necessidade exigida pelo Campus, o software AUTOCAD será necessário para a realização do projeto. Obtido o projeto da rede elétrica, será realizado um mapeamento e modelagem de fluxo de potencia pelo software OPENDSS e demanda exigida, e quais serão os impactos dessa nova demanda no sistema elétrico na região.

Palavras-chave: AUTOCAD; OPENDSS; Demanda

\section{Abstract}

About four years ago, the Campus of the Federal University of Santa Maria, located in the city of Cachoeira do Sul, is active and its activities are done on a provisional basis in properties in the central region and near the center. The Campus is currently in progress with its construction that will receive faculty, students and technical-administrative servers and will start with five undergraduate courses, and they are already in activity in the temporary Campus. An electrical distribution network project consists of improving the functioning of the Campus, taking into account that as it is still under construction, the Campus has provisionally provided electric power. The project proposal will meet the need required by the Campus, the AUTOCAD software will be necessary to carry out the project. Once the power grid project is obtained, a mapping and power flow modeling will be performed by the OPENDSS software and demand, and what will be the impacts of this new demand on the electric system in the region.

Keywords: AUTOCAD; OPENDSS; Demand 


\section{Introdução}

Iniciado em Agosto de 2014, o Campus de Cachoeira do Sul, da Universidade Federal de Santa Maria (UFSM-CS), realiza suas atividades provisoriamente em cinco imóveis localizados nas proximidades do centro da cidade até que a construção dos primeiros prédios do Campus, que estará localizado no bairro Passo de Areia, esteja em condições para que sejam recebidos os alunos, servidores técnico-administrativos e professores.

Para o melhor funcionamento do Campus, será necessário um projeto de rede de distribuição de energia elétrica, dado que até o momento tem-se a energia elétrica fornecida de forma provisória. O projeto de rede de distribuição, nada mais é do que o dimensionamento de transformadores, chaves fusíveis, tipo de poste e altura, equipamentos de proteção e iluminação necessários para suprir as necessidades de cada prédio e consequentemente de todo o Campus.

O objetivo do trabalho é propor um projeto da rede de distribuição de energia elétrica, utilizando normas da concessionária local, e o software AUTOCAD. A concessionária de Cachoeira do Sul é atualmente a RGE SUL filiada a CPF Energia.

A partir do projeto, mapear a rede e modelar a mesma com a ajuda do software OPENDSS, com o intuito de analisar o fluxo de potência da rede para constatar quais serão os impactos que a nova demanda ocasionará.

Obtido os valores de tensão e potência, observar quais serão os impactos que a nova demanda ocasionará na região do Campus.

Como o Campus ainda está em construção, não possui todos os prédios prontos, uma rede provisória foi realizada para suprir às necessidades momentâneas para o término da construção.

Na Figura 1 é possível observar essa rede provisória que está em funcionamento para o término da construção e na Figura 2 pode-se observar a construção de dois prédios do Campus.

Figura 1 - Rede Provisória de Distruição de Energia Elétrica

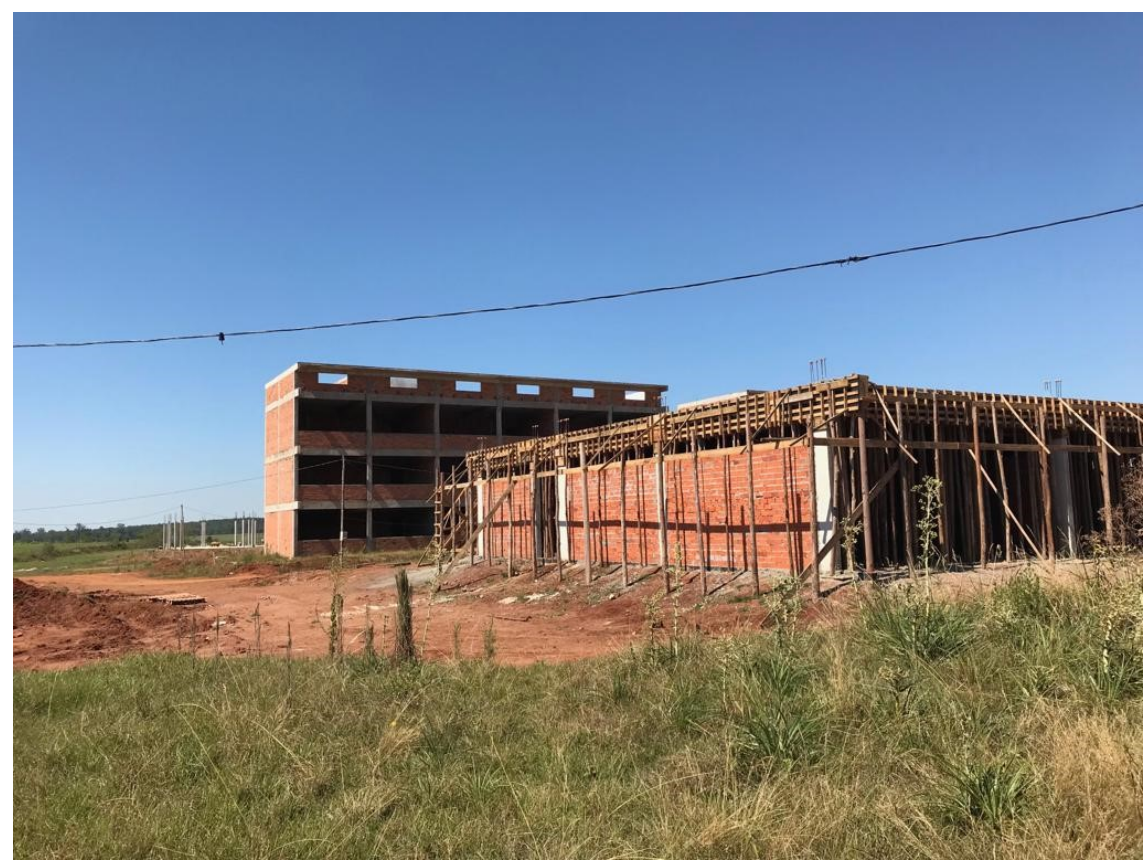


Figura 2 - Construção do Campus de Cachoeira do Sul

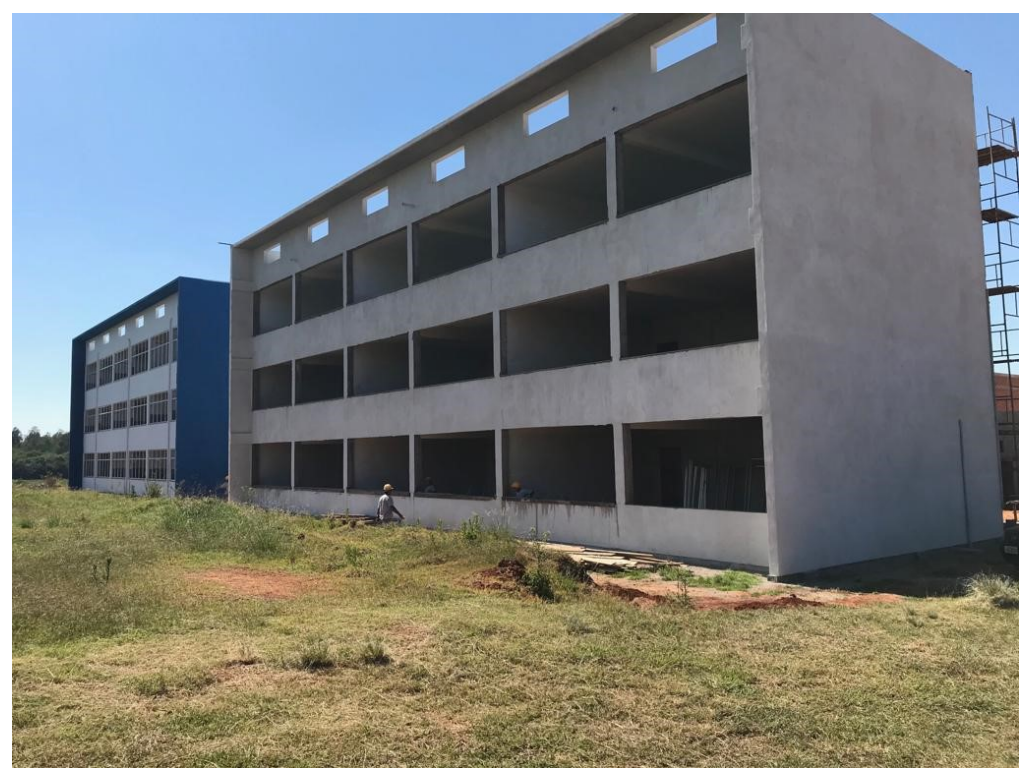

Para o funcionamento do Campus é necessário um projeto de rede de distribuição de energia elétrica, para fornecer energia elétrica aos prédios.

A Figura 3 mostra de um modo geral um projeto realizado provisoriamente para o Campus e a Figura 4 mostra em uma escala menor como seria disponibilizado os postes com os transformadores, chaves faca, chaves fusíveis, para-raios e outros equipamentos necessários no projeto, dimensionamentos de postes, e transformadores, local onde os postes estarão localizados, e a distância necessária entre cada poste e cada equipamento que for necessário utilizar.

Figura 3 - Projeto Provisório de Rede de Distribuição do Campus de Cachoeira do Sul

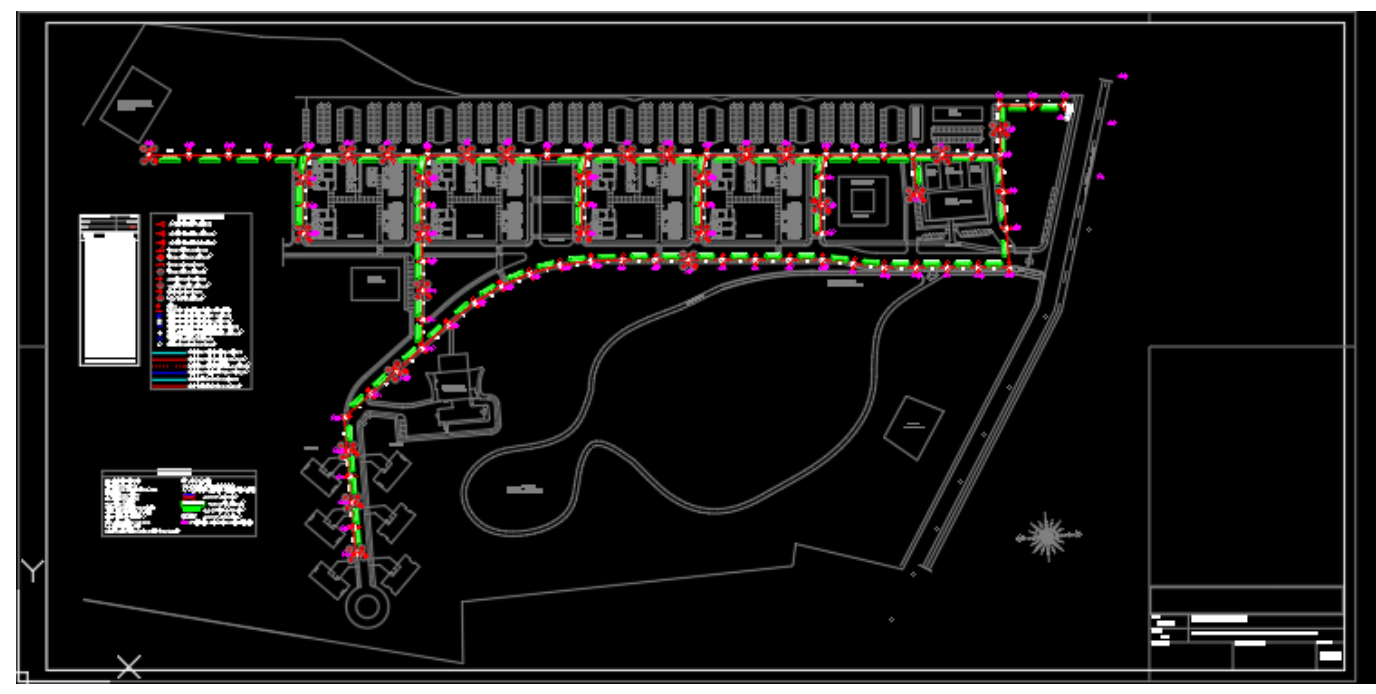


Figura 4 - Ampliação do Projeto Provisório

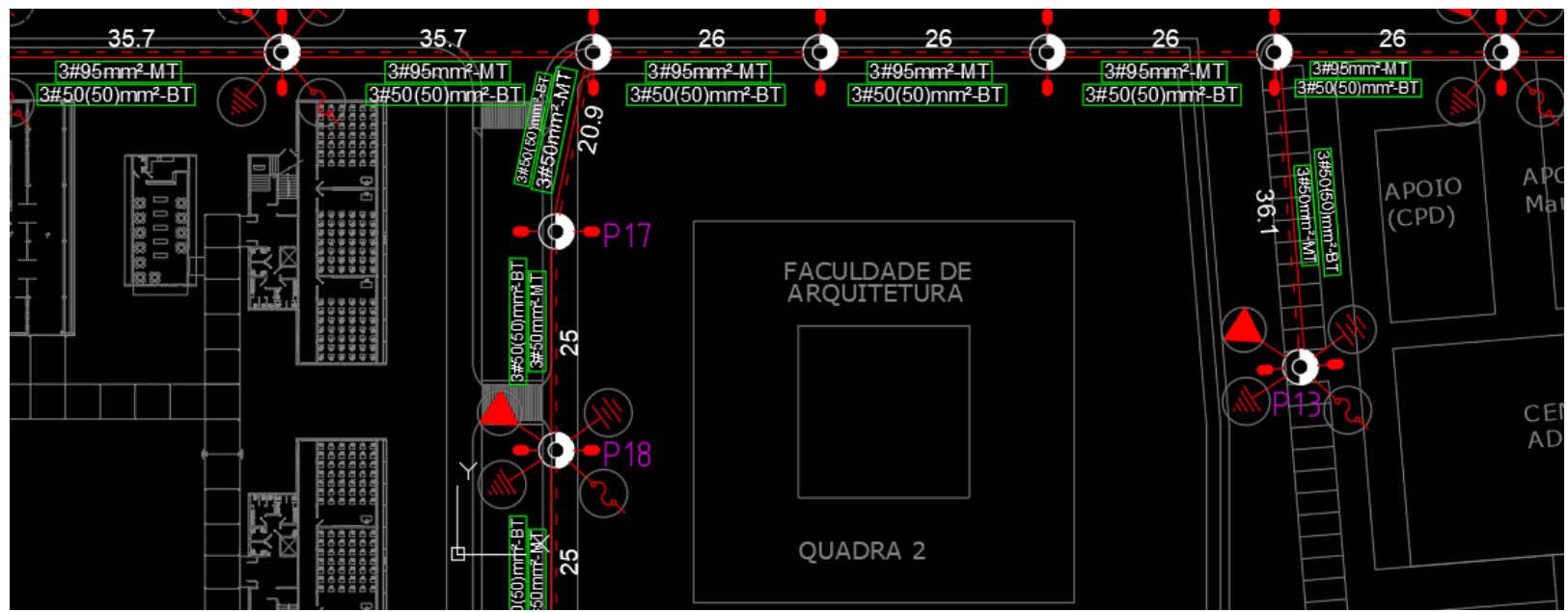

A partir da planta baixa do Campus e o dimensionamento elétrico das cargas de cada prédio, é possível propor um novo projeto de distribuição ao Campus, utilizando o AUTOCAD, levando em conta todas as necessidades exigidas.

Obtido a proposta do projeto, pode-se calcular a demanda pelo software OPENDSS, e quais serão as consequências para a região em que o Campus está instalado.

\section{Procedimentos Metodológicos}

Para iniciar o projeto é necessário ter em mãos a planta do Campus. A planta do Campus consiste no projeto de instalações elétricas para cada prédio, feita através do software AUTOCAD, com seu determinado quadro de cargas. E a planta geral do Campus para uma visão mais detalhada de como seria a posição para cada poste do projeto de rede de distribuição de energia elétrica.

O quadro de cargas é muito importante, pois com as potências necessárias definidas o projeto de distribuição se torna mais preciso.

Após definir as cargas necessárias para cada prédio, o projeto de rede de distribuição de energia elétrica pode ser realizado.

Feito a proposta de projeto de distribuição, também através do AUTOCAD, é possível por fim calcular a demanda de energia, através do mapeamento e modelagem da rede a partir do software OPENDSS, analisando o fluxo de potência da rede.

Realizado o mapeamento da rede, os impactos que a nova demanda do Campus ocasionará na região poderão ser analisados.

\section{Resultados e Discussão}

Como o projeto ainda está em andamento, foi feito um pré-lançamento da rede apenas para dispor a localização de cada poste necessário, a localização dos transformadores e o dimensionamento das redes de Média e Baixa tensão. Após realizar a análise do quadro de cargas pré-definido, e sabendo qual será a necessidade de potência para cada prédio, será possível concluir o projeto de rede de distribuição atendendo a demanda exata para cada prédio do novo Campus. 


\section{Considerações Finais}

É necessário ressaltar que o trabalho ainda está em andamento, portanto ainda não há nenhum resultado concreto.

\section{Referências}

KERSTING, W., D. Distribution System Modeling and Analysis. Las Cruces: CRC Press LLC, 2002. 314p.

KAGAN, N., DE OLIVEIRA, C. C. B., ROBBA, J.E.. Introdução aos sistemas de distribuição de energia elétrica. $1^{\mathrm{a}}$ edição São Paulo: Edgar Blücher, 2005.

ISSICABA, D. Fluxo de Potência para Rede de Distribuição de Energia Elétrica. Novas Edições Acadêmicas, 2016. 196p. 